\title{
浅析印尼儒教徒对其宗教元素教义和教仪的认识
}

\section{ANALYSIS OF INDONESIA CONFUCIANS UNDERSTANDING TOWARDS RELIGIOUS DOCTRINES AND ORDINANCES IN CONFUCIANISM}

\author{
Sugiato Lim \\ Chinese Department, Faculty of Humanities, BINUS University \\ Jln. Kemanggisan Ilir III No.45, Kemanggisan - Palmerah, Jakarta Barat 11480 \\ qyetohayashi@yahoo.com
}

摘要

印尼华人的日常生活在较大程度上被涂上了浓厚的宗教色彩。本文针对印尼儒教徒对其宗教的认识 进行分析。文章的第一部分从宗教的定义和元素展开，文章的第二部分将分别从印尼儒教徒对其宗教的 教义和教仪的认识来进行写作。在最后, 本文将对印尼儒教的一些特点以及印尼儒教徒对其宗教的认识 提出一个小总结。在这一部分, 我们将看到印尼儒教在印尼国土的特殊历史背景下, 争取、形成并发展 为独具印尼特色，符合印尼国情、民情的一门合法宗教。

关键词: 印尼儒教；宗教元素；教义；教仪；认识

\begin{abstract}
To a great extent, daily life of Indonesia Chinese community is filled with religious overtones. This paper basically analyzes the understanding of Indonesia Confucians towards their religion. The first part of this paper will be discussing about the general definition of religion and its religious elements. The second part will analyze the understanding of Indonesia Confucians towards their religious doctrines and ordinances respectively. In conclusion, overview regarding Indonesia Confucians and a special historical background of Indonesia Confucianism, which consists of its formation and development as a legal religion in line with Indonesia national conditions, social conditions and characteristic, will be presented.
\end{abstract}

Keywords: Indonesia confucianism, religious doctrines, religious ordinances, understanding 


\section{引言}

印尼在苏加诺执政时期曾经把儒教视为印尼国内合法宗教之一。在苏哈托长达三十余年的 统治下, 他对印尼华人采取了强制性的同化政策。关于当时印尼政府在文化方面对华人的同化, 主要表现在华文使用和教育、华人社团组织、华人文化习俗以及宗教信仰等方面。然而对印尼 人来说, 无论是原住民还是华人，宗教信仰是生活当中不可缺少的元素之一。对当时的印尼华 人来说, 儒教就是他们对祖籍国的一种精神上的寄托和纽带。因此, 印尼华人为了争取儒教在 印尼的再度合法化, 长期以来坚忍不拔。直到苏哈托下台以后, 印尼历任总统瓦希德再度恢复 了印尼儒教的合法地位。

既然儒教在印尼华人的心中具有如此崇高的地位, 笔者试图通过已有的相关文献和亲身体 验来进一步了解印尼华人对儒教的认识。让我们更加认识印尼华人是以怎么样的一个心态去信 奉儒教以及印尼儒教的特点所在。

目前而言, 对印尼儒教的研究成果或许不少。但他们的研究范围和视角都是比较广泛的。 而本文的研究范围只限于宗教元素的两个层面——教义和教仪。笔者将从具有普遍性的视角一 一老百姓的视角, 来叙述民众信徒对儒教的宗教元素的认识。

\section{内容}

\section{宗教的定义和元素}

\section{宗教的定义}

由于宗教学者对宗教所下的定义都不尽相同，所以每个人对宗教概念的接受度也会因人而 异。本文将以休斯顿・史密斯为 “宗教”一词所提出的宽泛定义为准。他认为, 宗教是为环绕着 一群人的终极关怀所编织成的一种生活方式。就算宗教采取一个比较狭窄的意义, 是指关怀人 与其存在的超越基础的结盟, 儒家仍然是一种宗教, 纵使它是一种缄默的宗教。（史密斯, 2006:196) 本文从此观点出发, 将儒学纳入宗教的范围内来进行写作。就印尼孔教而言, Hendrik Agus Winarso 博士在他的《Keimanan Dalam Agama Konghucu》一书封面上就指出, 孔教在孔子 诞生前名为儒教, 是一门具有悠久历史一一在孔子诞生前 2500 年 (约 5000 年) 已形成的宗教。 孔子不仅传承了儒教, 还完善、补充了儒教。孔子奉天之命成为人类心灵的木铎钟声。(Winarso, 2008 ）以下我们就站在这一立场一一儒教作为印尼国内合法的、刚刚复兴的宗教这个立场, 一 起探讨印尼儒教徒对自身宗教的认识。

\section{宗教的元素}

宗教的元素主要分成四个层面。其一是教义，即宗教的思想观念和道德理论的核心所在。 二是教仪, 即宗教的崇拜行为和礼仪规范。三是教主, 即该宗教的创始者。四是教团, 即宗教 
的教职制度和社会组织。基本上，印尼儒教已经形成完整的宗教系统，包含了以上四项元素。 但本文将从印尼儒教徒对其宗教的教义和教仪这两个层面来进行初步分析和写作。

\section{印尼儒教徒对其宗教元素的认识}

\section{对教义的认识}

印尼儒教已经形成一套完整的系统，包括其教义、仪式、独具一格的礼堂和宗教团体。就 教义而言, 在一般比较普遍的情况下来说, 在印尼儒教徒的脑海里已经形成一套他们对儒教的 模糊认识和界定。这种认识和界定是印尼儒教徒圈子里面公认的。他们会认为, 一个人只要家 里设有神祖牌、烧香拜拜就认定那个人是儒教徒。这种观念在老一辈华人脑子里尤其突出。在 他们对儒教的认识里甚至可以说他们没有意识到或者可以说他们根本不屑于知道有关那些更深 一层的宗教内涵。他们的儒教信仰不像一般的基督徒一一在家里自己应该持有一本圣经, 通过 读经来一步一步地思考并体会其中包含的教义。

不少儒教徒对儒教的教义还停留在原始而笼统的认识，诸如人应该好好做人、为人应该正 直、不得偷抢拐骗、孩子应当孝顺父母等为人的道理。但事实上，这些都是社会上大家所公认 的道德规范，也是所有宗教所提倡的。从本质上看，这一点倒是非常符合儒家的一贯作风和教 诲。我们无法断定在他们的认识里是否把这些道德规范和儒教的教义联系了起来。但我们也不 能完全否认他们的这种意识。笔者认为, 他们对儒教教义的认识是很笼统的, 而且是不成系统 的。问题在于许多印尼儒教徒对于挖掘其宗教教义的意识淡薄。我们很少会看到印尼儒教徒借 用教义来对人生作评判，也很少会听到他们说：“这种行为是违反教义的”。此外，印尼儒教并 不会像其他宗教对其教徒进行教义或福音传授。在这种条件下，他们只会将社会公认的道德规 范视为做人的原则。也许这种意识与教义无关，他们只是把它当作作为一个人类所应该具备的 道德规范。但同时，我们也很难否认他们在潜移默化中并非没有把这个潜在意识和宗教联系起 来。只不过，这种潜在意识并没有得以体现而已。

正因为许多印尼儒教徒不曾真正地认识其宗教的教义所在，可以说他们在很多时候，尤其 在别的宗教的冲击之下他们往往因为拿不出道理来而最后站不住脚，因为有不少儒教徒并未经 过教义传授的洗礼。笔者认为，当今的不少印尼儒教徒他们之所以改信别的宗教，其原因之一 是以上所说的现象。

现在，虽然印尼孔教会已经把四书五经翻译成印尼文译本，但这些经典并未真正普及到各 个儒教徒当中。甚至有多数信徒至今都不曾听过所谓儒教经典一一四书五经。可以说他们对儒 教教义的认识并非从阅读经典而来。也不是从传教士所传的福音而来。在他们意识里的仁、义、 忠、孝等儒教道德观念是来源于他们对理想人生道德观和价值观的自我总结。

虽然如此，并不意味着所有的儒教徒对教义的认识都是如此模糊不定。印尼孔教会也不断 地扩展范围, 完善组织, 增强年轻一代对宗教的认识和信仰。如今个别大学设有孔教学生会, 而且也积极地举办活动, 推广教义, 给信徒一个交流的平台。这也许是宗教体系不断完善的体 现，也是信徒对宗教认识的不断深入的表现之一。 
同时, 在另一方面我们可以感觉到儒教徒对生活的态度十分积极。甚至可以说具有强烈的 世俗性。这在另一种层面上却和儒教的积极入世的精神甚是符合。有时候他们甚至会以不解的 眼光去看待出家人。许多印尼儒教徒当中也非常排斥佛教所提倡的素食主义。也有少部分人误 认为, 的依佛教就等于放弃祖先崇拜。以至于, 有部分儒教徒对佛教持有抵触心理。但如果就 这样做出定论那未免也太片面了。因为我们不难发现在印尼华人的传统信仰中 “三教合一” 倾 向也非常突出。所以对于他们对佛教持有一定的抵触心理, 我们很难对此做出过多的评论, 只 知其然，未必知其所以然。

他们对佛教的抵触心理可以说并非由于佛教的教义而产生的。明确地说，那是他们对佛教 在履行教义的行为上的偏见。实际上，他们对佛教的核心教义-----慈悲并没有任何排斥的意味。

\section{对教仪的认识}

谈起儒教不能不谈祭祀, 因为它是礼仪的一种必要的形式。利玛窦曾经对儒教的祭祀礼仪 解释说: “这种在死者墓前上供的做法似乎不能指责为渎神, 而且也并不带有迷信的色彩, 因为 他们在任何方面都不把自己的祖先当作神, 也不并向祖先祈求什么或希望得到什么。” (谢桃坊, 2010:10）对古代的官员而言，祭祀礼仪的政治意义也许远远大于祭祀本身的原有意义。但这种 说法对于印尼儒教徒来说是不能成立的。

对印尼儒教徒来说, 他们的问题不在于儒教是否宗教, 或者祭祀是否迷信; 而在于他们如 何信教、如何把信仰诠释在生活当中。

实际上, 印尼儒教的仪式形式乍眼一看非常简单明了。他们似乎不熟悉种种繁琐的仪式形 式, 如儒家经典的《仪礼》, 《礼记》和《周礼》。根据他们所认识的儒教的宗教仪式就是每个月 初一、十五或每逢佳节到孔庙, 带上祭品、烧柱香、求平安、双手合十在神像面前拜一拜然后 就可以回家了。当他们祭天神、祭祖先的时候也是如此。但其实印尼儒教有成型的一套仪式, 只是这一套仪式还没有完全被广大信徒所接受。更准确的说, 这一套仪式, 虽然印尼孔教会正 在大力推广，但还没有完全普及到民众阶层。目前，仅有一些儒教积极分子才真正了解孔教会 制定下来的一系列宗教仪式的规范流程和形式并按照章法做礼拜。许多信徒则仍沿用原始的仪 式形式进行礼拜，所指的是到传统庙里拜神。

从仪式形式上可以看出, 印尼儒教徒对所谓的儒教礼仪的认识呈现出了一个简捷和随性的 特点。他们有时常用简单易懂的词语来概括自己的宗教信仰一一去庙里拜拜。可见，在他们对 儒教仪式的认识里, 所谓的仪式形式在经过他们的实际操作已被简单化了。笔者认为, 这个现 象的存在原因不排斥是因为对该宗教的教义的模糊认识所造成的。因为缺乏对儒教本质性的认 识导致了他们无法更深入地了解儒教, 无法从儒教的教义作为切入点来看待儒教。因此, 他们 经常使用描述仪式形式的简单词语来作为儒教的代称。

在宗教节日这方面，孔教会把农历正月初一的春节定为宗教大节日。其余的还有其他传统 节日，比如元宵节、清明节、中元节、冬至节等。这些传统节日都被纳入孔教节日行列里。在 民间，节日祭祀习俗具体的仪式操作当然也就按照传统的习俗来办。并没有受到孔教会对仪式 形式所制定的章法的影响。 
此外，在此笔者承接有关部分印尼儒教徒对佛教的抵触心理这个话题。从宗教仪式形式的 角度来看, 印尼儒教徒的祭祀除了呈现出简捷的特点, 还呈现出了随性的特点。就因为具有这 样的两个特点，使得部分儒教徒不太容易接受佛教里面繁琐而成系统的宗教仪式。也许在他们 看来, 那些繁琐的宗教仪式起了对人的制约和束缚的作用。当参加佛教仪式, 我们一般不宜随 便行动, 应该战战兢兢, 而且有许多繁琐的礼拜动作。儒教的这个特点也与天主教、伊斯兰教 等具有系统的宗教仪式的宗教不同。因此可以说, 这一点是印尼儒教在仪式形式上的一个特点。 但必须谨记的是, 这一特点只针对传统孔庙的仪式形式才有效, 并不包括孔教新兴的礼拜场所 一一礼堂。

此外, 需要强调印尼孔教中央理事会为了 “纯化” 孔教, 使之制度化, 变得像基督教、佛 教、伊斯兰教那样稳定，为此多次召开了全国孔教代表大会并确定了一整套的宗教仪式流程。 这套仪式有: “孔教信徒祈祷时的仪式由孔教士主持, 这些孔教士分为三等, 即 Haksu(学师)、

Bunsu(文士)、Kausing(教生), 他们类似基督教的传教士; 孔教的圣经叫做 Su Si(四书), 是用印尼 文写的; 孔教徒祷告完毕则说声 'Sian Cai' (善哉), 相当于基督教的 ‘阿门'” 等等。(张禹东, 2000:109）但至今, 这种系统化的仪式仍然没有普及到各地区的信徒民众, 更未被普遍信徒在 实际仪式上所应用。

\section{结语}

印尼儒教经过长时间的拼搏终于争取到了该有的宗教合法地位。因为这样一个特殊的历史 背景, 给印尼儒教的命运与前景添上了许多难以预测的成分。但也从此我们了解到, 在印尼华 人的心中儒教仍然占据了难以取代的地位。虽然印尼儒教徒对其宗教的教义和教仪的认识比较 笼统, 但这也呈现出了另一层面上的所谓的文化特点。但随着印尼儒教制度化的日益完善, 相 信信徒对其宗教元素的认识也会越来越清晰。

最后希望印尼儒教徒能够在这个特点的基础上再继续挖掘儒家的精神、学问及其文化内涵。 也希望能够在 “三教合一” 的基础上了解更多有关儒教和其他宗教，无论在教义还是教仪上的 融合点和不同点。这样在了解自身宗教的同时, 也会在互相了解的基础上和其他宗教和睦相处。 实现在印尼这样一个多宗教、多信仰的国家，宗教之间共存、共荣的美好理想。

\section{参考文献}

刘小枫 2007, 《儒教与民族国家》, 华夏出版社。

谢桃坊 2010, 《儒家与宗教——轮西方的儒教观念及相关的问题》, 《西华大学学报》第 29 卷第 2 期。 
休斯顿・史密斯 2006, 《人的宗教 (修订版)》, 海南出版社。

张禹东 2000, 《印度尼西亚全面同化政策下的华人宗教文化》，《华侨大学学报》第三期。

Winarso, H. A. (2008). Keimanan Dalam Agama Konghucu. Dahara Prize. 